\title{
A complexidade da simplicidade: a estrutura interna da imagem artística
}

\author{
The complexity of simplicity: \\ the inner structure of the artistic image
}

Prof. Juhani Pallasmaa, arquiteto

jpallasmaa@gmail.com

Professor de Arquitetura da

tradução Valentín Arechaga

University of Technology, Finlândia

"Tornar o simples complicado é comum, tornar o complicado simples, impressionantemente simples, isso é a criatividade". 1

Charles Mingus, músico de jazz

Estamos acostumados a pensar a simplicidade e a complexidade como polos opostos e excludentes. Quando falamos de fenômenos em lógica, essa visão pode ser aceita, mas nossas vidas mentais e as imagens artísticas não seguem as regras da lógica e da racionalidade. Enquanto os processos lógicos focalizam, a exploração artística se abre e se amplia; uma entidade lógica é excludente, enquanto uma imagem artística aspira à inclusão. Nossas mentes estão em fluxo constante de imagens, pensamentos, associações, lembranças e sonhos. E essa fusão existencial de categorias irreconciliáveis é o campo essencial da arte.

Em seu livro A Filosofia do Não: Filosofia do Novo Espirito Científico, Gaston Bachelard, filósofo francês da ciência e do imaginário poético (cujo livro A poética do espaço foi um dos textos mais influentes na teoria da arquitetura desde a sua publicação em 1958), argumenta que todo pensamento científico se desenvolve ao longo de um caminho predestinado: desde o animismo através do realismo, positivismo, racionalismo e racionalismo complexo até um racionalismo dialético (BACHELARD,1968, p. 15). "A evolução filosófica de uma peça especial de conhecimento é um movimento entre todas essas doutrinas na ordem indicada", ele argumenta (Idem, p. 16).

1 A citação se encontra originalmente em uma carta de Michael Matiisen ao autor em janeiro de 2013.

\footnotetext{
* Publicado originalmente em: Frank Lloyd Wright School of Architecture, Taliesin West, Scottsdale, Arizona, 20 março de 2013. Este texto foi apresentado como conferência em: Simplicity-Ideals of Practice, University of New York, 3- 5 Abril de 2013.
} 
Do meu ponto de vista, o pensamento artístico aspira a avançar na direção oposta; as artes avançam a partir de uma compreensão realista, racional e analítica do mundo voltando-se para uma experiência unificadora, mítica e animista. A arte procura re-mitificar, re-encantar, e re-erotizar nosso relacionamento com o mundo.

Paradoxalmente, a noção de simplicidade é utilizada comumente tanto no sentido pejorativo, quanto no reconhecimento de uma qualidade distintiva. Da mesma maneira, a noção de complexidade implica algo caótico e irresoluto, assim como uma unidade de um campo multifacetado dos fenômenos. Para confundir ainda mais o jogo entre as duas noções opostas nas artes, o significado fundamental da obra artística e arquitetônica está sempre além da obra material em si mesma, uma vez que serve como mediador para relações e horizontes da percepção, sentimento e compreensão. Como Maurice Merlau-Ponty aponta "Nós viemos não para ver a obra de arte, mas para ver o mundo segundo essa obra" (apud MCGILCHRIST, 2010, p. 409). A observação deste filósofo serve também para a arquitetura; um edifício enquadra e guia nossas percepções, ações, pensamentos e sentidos, ao invés de ser o próprio objetivo. Projeta uma narrativa épica da vida e da cultura humana. Como consequência a inteira complexidade da vida se converte em parte da obra artística e arquitetônica mais simples. Como Jean-Paul Sartre sugere: "Se o pintor nos apresenta um campo ou um vaso com flores os seus quadros são janelas que estão abertas no mundo inteiro" (SARTRE, 1978, p. 272). Essa abertura ao mundo dos sentidos e da interpretação é uma qualidade inerente da profunda imagem artística.

Ao invés de analisar e separar as coisas, a arte está fundamentalmente comprometida com a união e a fusão de opostos. Alvar Aalto, o grande arquiteto finlandês, argumentava que só mediante a união de opostos, uma obra artística pode conseguir significado. "Qualquer que seja nossa tarefa (...) Em todos os casos [de uma obra criativa] os opostos devem ser reconciliados (...) Quase todas as tarefas de design envolvem dezenas, frequentemente centenas, às vezes milhares de elementos contraditórios que são forçados a uma harmonia funcional pelo desejo do homem. Essa harmonia não pode ser conseguida mediante nenhum outro meio que aqueles da arte" (AALTO,1972, pp. 87-88).

A forma artística da arquitetura é logicamente uma categoria "impura" ou "confusa", pois contém e funde ingredientes de categorias contraditórias e até irreconciliáveis: materialidade e sentimento, construção e estética, fatos físicos e crenças, conhecimento e sonhos, passado e futuro, meios e fins. $\mathrm{Na}$ verdade, é difícil imaginar esforço mais complexo e internamente mais contraditório que a arquitetura. 
A tarefa de mediação e reconciliação da arquitetura é dupla: funde uma multidão de dimensões em um ente estruturado e experimental, e serve como uma fusão essencial do mundo e da própria pessoa. Tal matriz de fatores, aspectos, requerimentos, interesses contraditórios e sem relação, só pode ser levada a uma síntese - ou harmonia, utilizando a noção de Aalto - através de um processo criativo baseado em metáforas corporificadas e a fusão entre dúvida e certeza, emoção e juízo, intuição e sentimento, crença e desejo. Nessa fusão encontramos o milagre da imagem poética e da imaginação. Os projetos e as propostas arquitetônicas são metáforas espaciais vivenciadas que tem um grande impacto em um nível inconsciente e pré-reflexivo. Sir Colin St John Wilson, (o arquiteto da Biblioteca Britânica, cuja antiga casa em Cambridge abriga o arquivo de Wittgenstein) descreve esse impacto de maneira convincente:

É como se eu fosse manipulado por algum código subliminar, que não pode ser traduzido em palavras, que atua diretamente no sistema nervoso e na imaginação, misturando, ao mesmo tempo, indicações do significado com vívidas experiências espaciais como se fossem uma coisa só. Eu acredito que esse código atua tão diretamente e vívidamente sobre nós porque ele é estranhamente familiar; isto é na verdade a primeira linguagem que nós aprendemos, muito antes das palavras (...) que agora é lembrada através da arte. Somente a arte sustenta a chave para revivê-la (...) (ST JOHN WILSON, 1979).

A obra completamente redutora espacialmente de Fred Sandback exemplifica o jogo perceptivo da imagem extremamente simples com uma experiência inesperadamente complexa. Em sua essência material suas obras são tão mínimas como uma obra de arte pode ser: apenas umas poucas linhas esticadas no espaço. As obras podem ser consideradas como "minimalismo", mas o artista não gosta desse rótulo, prefere chamá-las de "esculturas" ou "construções". A noção de minimalismo é completamente problemática, e geralmente a caracterização está baseada em uma compreensão formal e superficial da obra, ou em uma deliberada simplificação formal como um preconceito estilístico. Sandback define as suas obras como "simples fatos" sem nenhuma intenção representacional ${ }^{2}$. Contudo, a afirmação de sua intenção não pode evitar o pro-

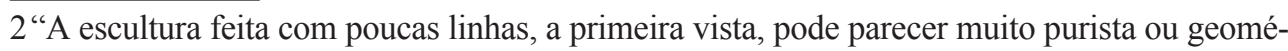


cesso perceptivo e cognitivo que suas obras mobilizam na mente do observador. Independentemente do ponto de vista do artista, tais obras completam suas gestalt automaticamente na mente do observador em busca de seu significado. $\mathrm{Na}$ famosa descrição de Frank Stella: "O que você vê é o que você vê"3, mas no fenômeno da arte o que você experimenta nunca é o que você realmente vê.

A complexidade oculta das configurações espaciais do Sandback surge de nossos mecanismos perceptivos, do poder da gestalt geométrica e da leitura convencional de espaços em um desenho, assim como da ambivalência e tensão entre o material e as realidades imaginativas na arte. As suas linhas quase imateriais de fio de acrílico, tensionadas no espaço, são essencialmente questões filosóficas: Por que e como surge uma imagem espacial e qual é a realidade dessa irrealidade? Por que uma coisa existe invés de não existir?

As linhas de Sandback nos fazem ver figuras especificamente formadas no espaço, um volume imaginário no solo ou suspenso no ar. As linhas conectadas, configuradas como triângulo numa esquina de uma galeria, ou suspensas entre a parede e o solo, perdem a sua natureza linear como um desenho e se convertem em espaços imateriais de materialidade idealizada. $\mathrm{O}$ ar dentro da figura imaginária parece mais denso e de uma consistência levemente diferente que o ar fora da figura. O plano inexistente adquire um peso experiencial. Essa alquimia artística é particularmente efetiva nas construções de quatro linhas que nos fazem conceber um plano retangular apoiado numa parede ou afastado dela. O retângulo imaginado transforma-se numa lâmina de matéria transparente como vidro e a construção parece paradoxalmente invocar um volume imaginário e anular o peso e a gravidade. O "plano" exterior parece ter o perigo de cair, e o "plano" apoiado contra a parede parece se dobrar com seu próprio peso. Esse tipo de experiência é provavelmente resultado da capacidade empática de nossos neurônios espelho; sentimos o plano imaginário através de nossa inconsciente mímese corpórea e da combinação de nosso senso de equilíbrio e gravidade. De forma similar, experimentamos o peso e o movimento idealizado das peças de aço do Richard Serra através de nossos músculos e ossos, pele e senso de equilíbrio. Nós renovamos o que vemos através da capacidade empática do nosso corpo.

trica. A minha obra não é nada disso. Minhas linhas não são destilações ou refinamentos de nada. Elas são simples fatos, aspectos de minha atividade que não representam nada além delas mesmas. As minhas peças são oferecidas como situações concretas e literais e não indicações de nenhum tipo." Fred Sandback, "Untitled" em Fred Sandback, eds. Friedeman Malsch and Christiane Meyer-Stoll, Hatje Cantz Verlag, Ostfildern-Ruit, 2005, 106.

3 Fonte não identificada. 
Truques visuais e ilusões são meras demonstrações da psicologia ou da mágica do ilusionista, uma vez que o impacto artístico pede pelo conteúdo metafórico e existencial. As obras de arte são sempre sobre o mundo e a própria situação de vida e consciência do observador. Quais são as metáforas delineadas nas construções do Sandback? As obras dele questionam as suposições do realismo ingênuo e nos revelam a relatividade e a natureza dialética de nossa experiência da realidade. Nós não vivemos num mundo dado e objetivo, vivemos em um mundo de nossa própria criação. "Num mundo, a imagem não tem um significado certo (...) mas um mundo inteiro refletido numa gota de água", como o grande diretor de cinema russo Andrei Tarkovsky sugere. (TARKOVSKY, 1986, p110)

A obra artística tem sempre uma existência dupla: ela ocorre na realidade da matéria e execução, e ainda, por outro lado, no mundo imaginário da percepção, pensamento e emoção.

Geralmente não vemos a silhueta da figura como uma linha independente porque percebemos o objeto fisico que ela encerra e chamamo-lo de objeto. Não experimentamos primariamente o aspecto fisico da escultura, mas sim o volume e a forma da peça. Em uma obra arquitetônica não experimentamos o espaço físico sem significado porque estamos afetados pelos espaços articulados arquitetonicamente que possuem significados específicos. A tensão entre as duas realidades é fundamental para a mágica da arte.

O ideal supremo de toda arte é fundir a complexidade das experiências humanas em uma imagem singular, ou "o sentimento oceânico" da unidade e unicidade da criança no útero, como o pensamento psicoanalítico sugere. Rainer Maira Rilke escreve de maneira emocionante sobre os ingredientes da condensação poética: "Os versos não são, como as pessoas imaginam, simplesmente sentimentos (...) são experiências. Por amor a um único verso, deve-se visitar muitas cidades, homens e coisas, deve-se conhecer animais, deve-se sentir como os pássaros voam e saber o gesto com que as pequenas flores abrem pela manhã" (RILKE,1992, p. 26). O poeta continua com uma lista de uma página inteira de experiências requeridas para escrever um único verso. Ele enumera caminhos rumo a regiões desconhecidas, encontros e separaçãoes inesperados, doenças da infância, retiros à solidão, noites de amor, gritos de mulheres em trabalho de parto e tendendo a morte. Mas tudo isso ainda não é suficiente para criar uma única linha de um verso. Segundo o poeta, devemos esquecer tudo isso e ter paciência para aguardar o retorno destilado dessas experiências. Apenas depois de todas as nossas experiências se tornarem nosso próprio sangue, "não antes disso pode acontecer que, na hora mais estranha, a primeira palavra de um verso surja em seu interior e venha a tona a partir dele". (RILKE, op.cit., p. 27) 
Uma forma especial de complexidade na simplicidade nas regiões mentais e artísticas é o arquétipo. O conceito nasce da ideia de Sigmund Freud de "resquícios arcaicos" da mente. Mais tarde, Carl C. Jung definiu o arquétipo como tendência de uma imagem para evocar diferentes asociações, sentimentos e significados na memória coletiva. Mais uma vez, a abertura e categorização do fenômeno mental é essencial - uma riqueza de asociações mediada por uma imagem identificável coletivamente, em vez de um significado fechado e específico. As obras de arte muitas vezes se aproximam do conceito de arquétipo.

Barnett Newman, pintor abstracto expresionista norteamericano, intitula algumas das suas pinturas, consistindo em um elemento lineal sobre o fundo de outra cor, Onements ${ }^{4}$. O pintor condensa uma multidão de experiências existenciais dentro de uma imagem extremamente simples. O quadradro negro sobre fundo branco de Kazimir Malevich, assim como as pinturas monocromáticas de Yves Klein e os espaços do céu [skyspace] de James Turrel, são similarmente "onements", que fundem a multiplicidade de experiência dentro de um todo indivisível. Não existem "elementos" nesses trabalhos, apenas sua singularidade. Eles representam simplicidade ou complexidade?

A dificuldade de determinar uma obra de arte como simples ou complexa, surge do fato de que qualquer imagem artística - pintura, poema, peça musical ou o espaço arquitetônico - existe simultaneamente em duas regiões: primeiramente como fenômeno material no mundo físico, e, segundo, como imagem mental na experiência do indivíduo. No primeiro sentido, o Quadrado Negro [Black square] de Malevich representa só uma figura geométrica sobre o fundo branco executada pelo pincel do pintor. Contudo, a superfície pintada, rachada pelo tempo, dá à obra um sentido de unicidade e autenticidade, realidade e idade, para além da essência geométrica, como ícone e como aura. Suas imagens mentais são muitas coisas ao mesmo tempo, conectadas com campos existenciais, filosóficos, metafísicos, religiosos e simbólicos. A imaginação e autonomia do observador na procura de signifição estabelece um processo sem fim de associação e interpretação dinâmicas. É o indefinível provocativo e a abertura da sugestão poética que outorga sua riqueza evocativa, sentido da vida e complexidade mental. Simplicidade se transforma em complexidade labiríntica. A obra artística ou arquitetônica é sempre um rizoma mental sem fim. Privado da sugestão enigmática da imagem poética, um quadrado se mantém como mera figura sem vida, sem um sentido mais profundo ou capacidade de evocar emo-

4N.T.: Mantive o termo Onement sem tradução na medida em que se refere ao título da obra de Barnett Newman. 
ções. A simplicidade arquitetônica profunda condensa imagens e significado semelhantemente. Também na arquitetura, a simplicidade formal, privada de intenção poética, tem como resultado uma mera construção.

A Casa Engelmann, construída e desenhada em Vienna por Ludwig Wittgenstein em 1928, é um caso esclarecedor sobre a interação necessária entre a simplicidade formal e a complexidade do conteúdo e do contexto. Concebida por um dos grandes filósofos do século XX, é sem dúvidas produto de pensamento sério e preciso, o qual reduziu todos os elementos arquitetônicos a sua essência mínima.

O fato de que a laje do andar intermediário tenha sido cinzelada e refeita três centímetros mais alto, nos convence da firme ambição arquitetônica do autor. Contudo, a obra permanece curiosamente muda e sem vida. $\mathrm{O}$ que parece faltar nessa obra de arquitetura ultra-racional é a complexidade mental e o diálogo com o contexto, o sentido de encarnação e sensualidade poética. "Eu não estou interessado em construir um edifício, mas em apresentar a mim mesmo a fundação de todos os edifícios possíveis" confessava Wittgenstein ${ }^{5}$. Parece que exatamente essa generalidade racionalizada torna muda a casa Engelmann; é como se fosse uma fórmula lógica para uma casa em vez de um edifício específico na "carne do mundo", utilizando a noção sugestiva do Maurice Merlau-Ponty ${ }^{6}$. A obra dificilmente evoca associações ou sentimentos, ela meramente existe como si mesma.

A arquitetura minimalista de hoje, geralmente implica a aplicação de um preconceito estilístico formal, enquanto que a simplicidade artística significativa e a abstração é resultado de um processo trabalhoso e gradual. A palavra "abstração" sugere enganosamente uma subtração ou uma redução da signifição, mas uma abstração artística rica, que tem a capacidade de despertar nossas emoções e alimentar nossas imaginações, só pode surgir do processo oposto de destilação ou compressão. Constantin Brancuso, o mestre escultor, nos dá um conselho significativo: "A simplicidade não é um fim na arte, mas se chega à simplicidade apesar de si mesmo, em aproximação à verdadeira essência das coisas (...) simplicidade é no fundo complexidade e cada um deve ser nutrido de sua própria essência para compreendermos seu significado" (BRANCUSI, 1926).

A verdadeira abstração condensa ingredientes da busca criativa em uma singularidade artística. Ao mesmo tempo, a obra toma certa distância da subjetivida-

\section{Wittgenstein. Wikipédia}

6 Maurice Merlau-Ponty, "The Intertwining-The Chiasm", The Visible and the Invisible, Claude Lefort, editor, Northwestern University Press, Evanston, 1969. O autor descreve a noção de carne da seguinte forma: "Meu corpo está conformado pela mesma carne do mundo (...) e além disso (...) a carne do meu corpo é compartilhada pelo mundo (p.248), e; "A carne (do mundo ou a minha) é (...) uma textura que volta para si mesma e se autodetermina” (p.146). 
de do autor à universalidade e ao anonimato. Balthus (Balthasar Klossowski de Rola) um dois maiores pintores figurativos do século XX, faz um comentário surpreendente e instigante sobre a expressão artística: "Se a obra apenas expressase o autor, não valeria a pena sua criação (...) expressar o mundo e compreendê-lo, isso é o interessante para mim”. (apud ROY, 1996, p.18) Mais tarde, Balthus reformularia seu argumento: "As grandes pinturas devem ter um significado universal. Isso já não acontece hoje e é por isso que eu quero dar à pintura o seu anonimato perdido, porque quanto mais anônima a obra, mais real ela é”. (BALTHUS, 2001, p 6.) $\mathrm{O}$ mesmo argumento pode ser utlizado seguramente na arquitetura.

Todas as obras de arte significativas são microcosmos, representações miniaturizadas e condensadas de um mundo metafórico e idealizado. Este é um universo interno da obra mesma, o Weltinnenraum, utilizando a bela noção de Rainer Maria Rilke (apud ENWALD, 1997, p 8.). A imagem poética constantemente guia nossas mentes para novos contextos, a claridade convida à obscuridade $\mathrm{e}$ a simplicidade formal se converte em complexidade experimental. "O que há de mais misterioso que a claridade?" pergunta o poeta Paul Valery. (VALERY, 1956, p. 107.) William James, o psicólogo visionário norteamericano descreve a fluidez essencial e a abertura infinita do imaginário mental: "Cada imagem definida na mente é impregnada e tingida na água livre que corre ao seu redor. Assim viaja o sentido das suas relações, próximas e remotas, o débil eco de onde isso vem para nós, o sentido nascente para onde nos dirigimos. O significado, o valor da imagem, está na auréola ou na penumbra que nos rodea e que a acompanha”. (JAMES, 1983) A claridade só tem valor na arte quando projeta um campo potente de cruzamentos entre associações e impressões. A mais simples imagem poética, que surge do autêntico processo de destilação artística, segue sugerindo imagens e ecos, em uma procura sem fim por novos significados.

As imagens associativas da arte são existenciais e não estéticas, e dirige inteiramente nossos sentidos de ser. Em vez de meramente oferecer prazer visual, a arquitetura também desperta profundas capas da mente e o sentido de si próprio. Ou mais precisamente, verdadeiras imagens arquitetônicas evocam memórias multisensoriales e corporificadas, fazendo a entidade arquitetônica parte de nossa constitução corpórea e sentido de existência. Através de nosso corpo, nos re-encenamos e imitamos inconscientemente qualquer coisa que encontramos no mundo. Como estudos neurológicos atualmente confirmaram, cada obra de arte e de arquitetura significativas mudam nosso pensamento, comportamento e nossa auto-compreensão. 
Além da esfera das artes, a interação da simplicidade e complexidade é especialmente impresionante e inspiradora no mundo biológico e natural. Aqui a constante interação de simples princípios e casualidades cria um fluxo sem fim de variações e complexidades sutis. A complexidade do mundo biológico é normalmente subestimada porque temos a tendência de sobrevalorar a nossa própria compreensão e realizações. Edward O. Wilson, o primeiro mirmecologista e porta-voz do Biophilia, a ciência e ética da vida, traz o desconcertante argumento de que o "superorganismo" da comunidade de formigas cortadoras de folhas é "uma das obras-prima da evolução, repetitivo e preciso e mais complicado que qualquer invensão humana e inimaginavelmente antigo" (WILSON, 1984, p. 37). Sem surpresa, os complicados sistemas de trânsito são traçados hoje utilizando modelos de comportamento das formigas, e as computadoras super-rápidas são desenvolvidas usando nosso próprio sistema neuronal como modelo. Ao mesmo tempo, Semir Zeki, neurologista que ampliou o recente conhecimento da neurociência nos fenômenos artísticos, sugere "a teoria de estética com bases biológicas.” (ZEKI,1991, p 1). O que é a beleza se não for o princípio de trazer complexidade dentro da deslumbrante coerência aparentemente simples. Joseph Brodsky declara sua visão como um grande poeta: "O propósito da evolução, acredite ou não, é a beleza” (BRODSKY, 1995, p. 208).

Gostaria de terminar meu ensaio sobre ação recíproca entre a simplicidade e a complexidade nas artes com a afirmação poderosa e poética de Constantin Brancusi sobre os requisitos da verdadeira obra artística: "A arte deve outorgar subitamente, de repente, a surpresa da vida, a sensação de respirar" (SHANES, 1989, p 67).

Recebido em: 10.05.2014 | Aprovado em: 20.06.2014

AALTO, Alvar. "Taide ja tekniikka" (Art and technology), lecture, Academy of Finland, October 3, 1955, In: Göran Schildt, ed., Alvar Aalto Luonnoksia (Alvar Aalto Sketches). Otava Publishing, Helsinki, 1972.

ALBORNOS, Christina Carrillo de. Balthus in His Own Words: A Conversation with Christina Carrillo de Albornos. Assouline, New York, 2001.

BACHELARD, Gaston. The Philosophy of No: A Phi- losophy of the New Scientific Mind. The Orion Press, New York, 1968.

BRODSKY, Joseph. "An Immodest Proposal". In: On Grief and Reason. Farrar, Straus and Giroux, New York, 1995.

ENWALD, Liisa. "Lukijalle" (To the reader), Rainer Maria Rilke, Hiljainen taiteen sisin: kirjeitä vuosilta 1900-1926 (The silent innermost core of art: letters 
JAMES, William. Principles of Psychology (1890). Harvard University Press, Cambridge, Massachusetts, 1983.

MCGILCHRIST, Iain. The Master and His Emissary: The Divided Brain and the Making of the Western World. Yale University Press, New Haven and London, 2010.

MERLEAU-PONTY, Maurice. "The Intertwining-The Chiasm", In: The Visible and the Invisible. Claude Lefort (editor). Northwestern University Press, Evanston, 1969.

RILKE, Rainer Maria. The Notebooks of Malte Laurids Brigge. W.W. Norton \& Company, London, 1992.

ROY, Claude. Balthus, Little, Brown and Company. Boston - New York - Toronto, 1996.

SARTRE, Jean-Paul. What Is Literature? Peter Smith (Ed), Glouchester, Massachusetts, 1978.

SHANES, Eric. Brancusi. Abbeville Press, New York, 1989.

TARKOVSKY, Andrei. Sculpting in Time - Reflections on the Cinema. The Bodley Head, London, 1986.

VALERY, Paul. "Eupalinos or the Architect", in Dialogues. Trans. William McCausland Stewart, Pantheon Books, New York, 1956.

WILSON, Edward O. Biophilia: The Human Bond With Other Species. Harvard University Press, Cambridge, Massachusetts, 1984.

ZEKI, Semir. Inner Vision: An Exploration of Art and the Brain. Oxford University Press, Oxford, 1999.

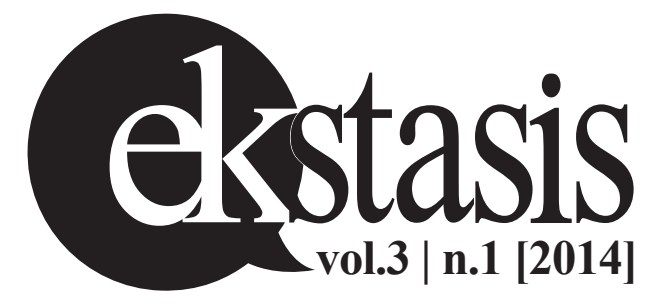

